\title{
ULTRASOUND-GUIDED FASCIAL BLOCK OF THE INTERCOSTAL NERVES, NEW MULTIMODAL APPROACH FOR UPPER ABDOMEN LAPAROTOMIES: A DESCRIPTIVE STUDY.
}

\author{
M. T. Fernández Martín, C. Bravo Ovadia, B. Cano Hernandez. Hospital Medina del Campo (Valladolid)
}

Pain management is a fundamental component of the multimodal rehabilitation strategy for abdominal surgery. Currently, the laparoscopic approach to abdominal pathologies has modified the analgesic approach, favoring the use of abdominal wall blocks versus epidural analgesia. Since 2015 we have been conducting ultrasound-guided fascial block of the intercostal nerves at the level of the 8th rib for open cholecystectomy (modified BRILMA).

We conducted a review of the postoperative analgesic techniques applied in the superior laparotomies at Hospital Medina del Campo.

Study goal: To evaluate the prevalence and intensity of acute postoperative pain in patients undergoing upper abdominal laparotomy and to assess the effectiveness of different analgesic techniques.

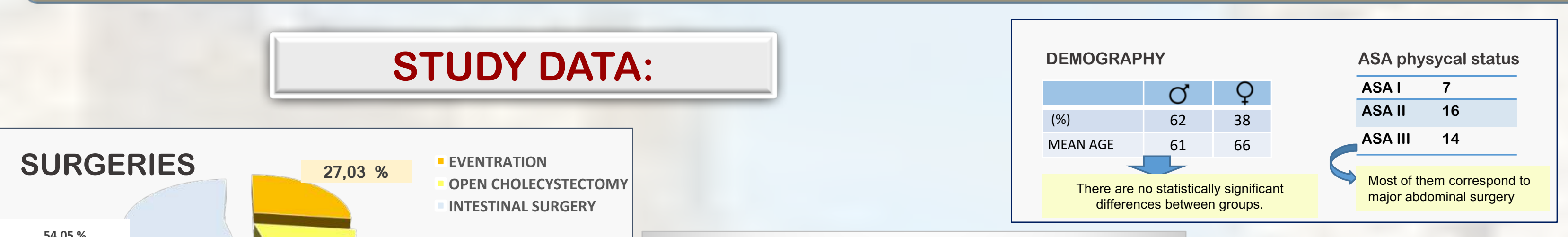

$54,05 \%$
(50\% Reconverted
surgeries)

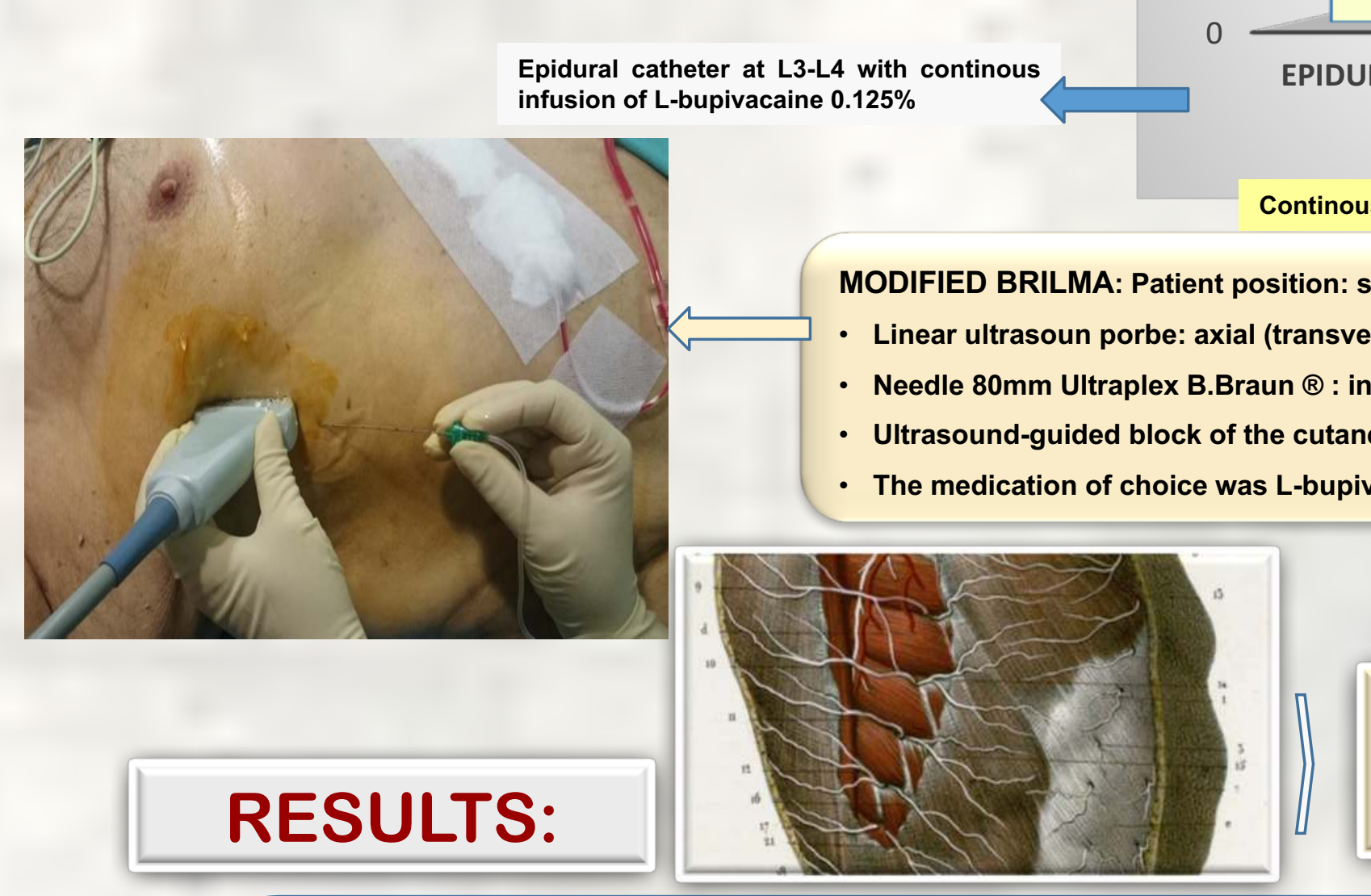

ANALGESIC TECHNIQUES

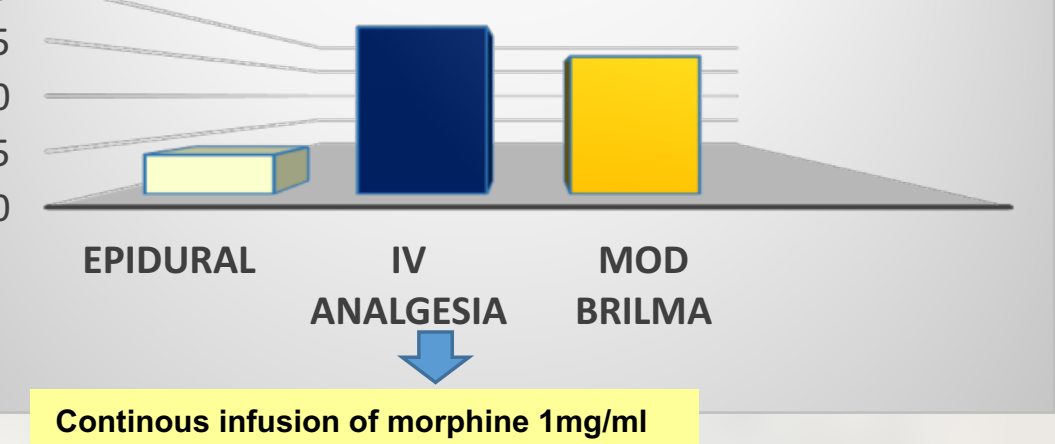

Needle $80 \mathrm{~mm}$ Ultraplex B.Braun ${ }^{\circledR}$ : in-plane approach, cephalad-oriented needle.

Ultrasound-guided block of the cutaneous branches at 8 th rib level, midaxillary line

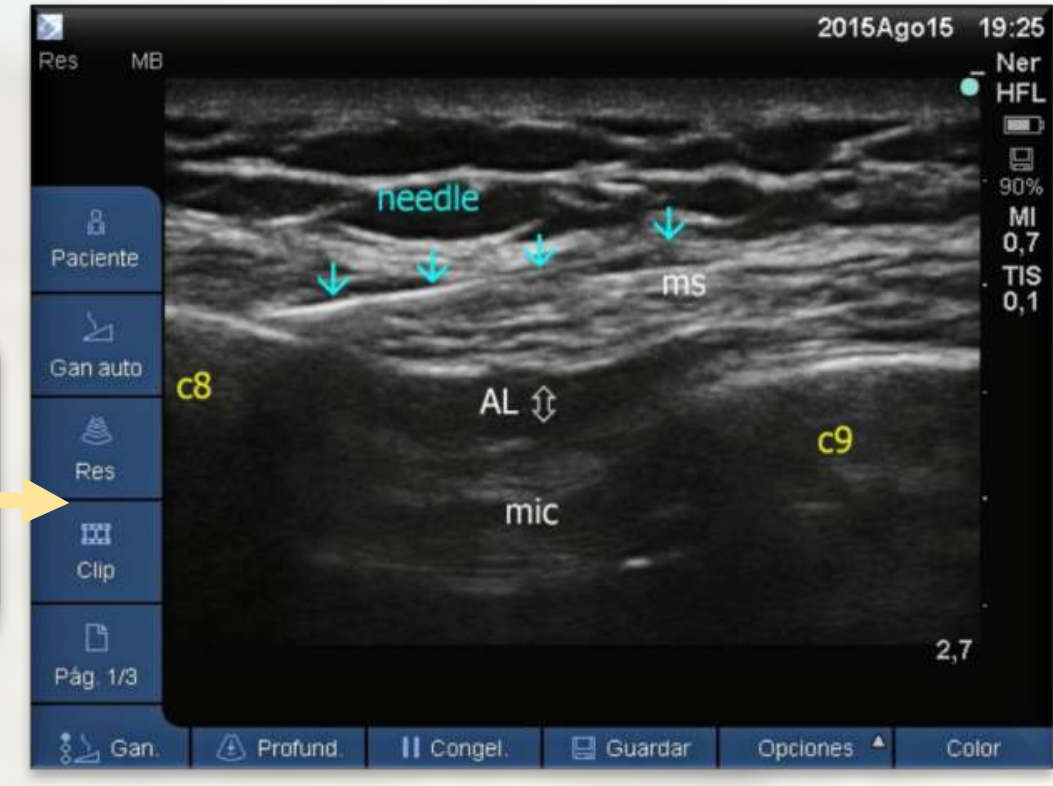

The local anesthetic injected at this level blocks the lateral and anterior cutaneous branches of the intercostal nerves. 7th-11th, wich give innervation to the upper abdominal wall.

We've represented the results of the opiods administration in the OR, the pain scores and the aditional needs of morphine at 48 hours in table 1.

\begin{tabular}{|l|c|c|c|c|c|} 
& $\begin{array}{c}\text { Number } \\
\text { of } \\
\text { patients }\end{array}$ & $\begin{array}{c}\text { Fentanyl in the OR } \\
(\mu \mathrm{g})\end{array}$ & EVN $<5$ & EVN $>5$ & $\begin{array}{c}\text { Additional } \\
\text { Morphine }\end{array}$ \\
\hline Epidural analgesia & 4 & 300 & 3 & 1 & $7 \mathrm{mgr}$ \\
\hline IV morphine & 17 & $300-600^{\star}$ & 12 & 5 & $<10 \mathrm{mgr}$ \\
\hline Modified BRILMA & 15 & $150-600^{\star *}$ & 10 & 5 & $<10 \mathrm{mgr}$ \\
\hline
\end{tabular}

* The total ammount of fentanyl used in the OR depended on the kind of surgery and its complexity.

** The lower fentanyl dose $(150 \mu \mathrm{g})$ corresponds to patients in whom the block was performed before surgery, and the maximum dose $600 \mu \mathrm{g}$ was used in reconverted surgery when the block was performed at the end.

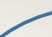

There were differences in pain scores between groups in the postoperative period. Table 2.

\begin{tabular}{|c|c|c|c|c|c|}
\hline EVN $>5$ & $N^{\circ}$ of patients & $6 \mathrm{~h}$ & $12 \mathrm{~h}$ & $24 \mathrm{~h}$ & $48 \mathrm{~h}$ \\
\hline IV Morfina & 5 & 3 & 2 & 0 & 0 \\
\hline Modified BRILMA & 5 & 0 & 1 & 2 & 2 \\
\hline
\end{tabular}

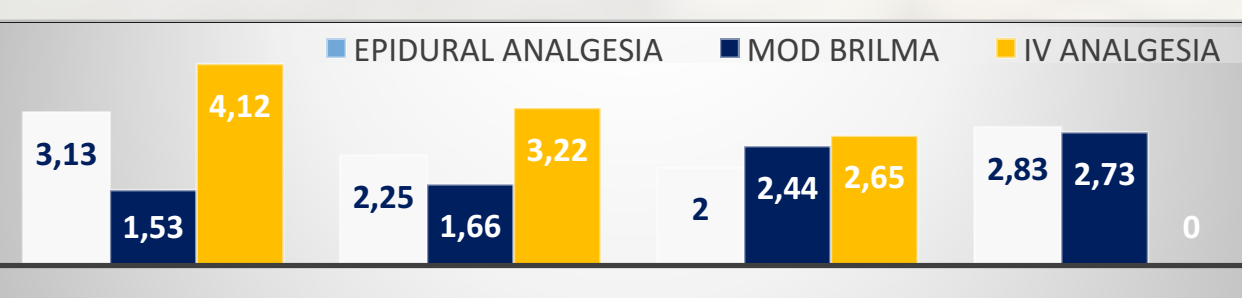

EVA 6H

EVA $12 \mathrm{H}$

EVA $24 \mathrm{H}$

EVA 48H We found a better pain managment in the modfified BRILMA group (EVN $<2$ at 12
houres later), wjth no differences after 48 hours between groups (mean EVN $<3$ ).

In one case we performed the block because of the high needs of morphine in the first 12 hours (18mgr).

After the $48 \mathrm{hrs}$ when the block was performed, patients will need aditional morphine dose as a multimodal strategy for mild to severe pain.

Postoperative complications:

- Sedation and/or disorientation (38\%,all of them from the IV morphine group)

- Postoperative nausea and vomiting (5 patients, no differences between groups), hypotension (1 patient epidural analgesia group).

- Lack of collaboration in respiratory rehabilitation because of sedation in $\mathbf{5 0 \%}$ of IV morphine group patients.

In abdominal wall surgery (eventration) and open cholecystectomy, the ultrasound guided fascial block of the intercostal nerves performed uni or bilateral, present a higher quality of recovery (time-to-ambulation and diet tolerance) and a better pain management (EVN <2).

In open major surgery we didn't see any advantage in pain management between IV morphine and the modified BRILMA block, just the lower morphine dose in the first 48 hours (0/5 vs $7 / 11)$ in the block group with less sedation. 